\title{
Measuring Enjoyment of an Interactive Museum Experience
}

\author{
Elisabeth M.A.G. van Dijk \\ University of Twente \\ Human Media Interaction \\ PO Box 217, 7500 AE Enschede \\ The Netherlands \\ 0031534893781 \\ e.m.a.g.vandijk@utwente.nl
}

\author{
Andreas Lingnau \\ University of Strathclyde \\ Dept. of Computer \& \\ Information sciences \\ Glasgow \\ UK \\ lingnau@ieee.org
}

\author{
Hub Kockelkorn \\ Museon \\ Stadhouderslaan 37 \\ 2517 HV The Hague \\ The Netherlands \\ 0031703381338 \\ hkockelkorn@museon.nl
}

\begin{abstract}
Museums are increasingly being equipped with interactive technology. The main goal of using technology is to improve the museum-going experience of visitors. In this paper, we present the results of a study with an electronic quest through a museum aimed at children in the age of 10-12. We wanted to find out whether personalization of the quest effects enjoyment. For this purpose we involved an interactive multi-touch table in the experiment, which also offered the opportunity to add the element of collaboration. We compared a group that did the original nonpersonalized quest with a group that did the personalized quest. This last group interacted with the multi-touch table to personalize the quest before they started on it. No significant differences were found between the experimental groups. We did find many differences between the children of age 10-11 and those of age 11-12, on almost all measurements. On this aspect we present some methodical results about measuring enjoyment and intrinsic motivation with children of 10-12 years old.
\end{abstract}

\section{Categories and Subject Descriptors}

H5.2. Information interfaces and presentation: User interfaces. K.3.m Computers and education: Miscellaneous.

\section{Keywords}

Personalization, multi-touch interaction, child-computer interaction, enjoyment, intrinsic motivation.

\section{INTRODUCTION}

The role of museums has been shifting from mainly conserving, collecting, research, exhibiting and educational institutions to institutions that are competitive and popular as well [12]. Nowadays museums have to compete more and more with other activities and cultural centers that focus both on education and entertainment [7]. One way for museums to deal with these challenges is to improve the museum-going experience for children by making children's visits more dynamic, engaging and enjoyable.

Permission to make digital or hard copies of all or part of this work for personal or classroom use is granted without fee provided that copies are not made or distributed for profit or commercial advantage and that copies bear this notice and the full citation on the first page. To copy otherwise, or republish, to post on servers or to redistribute to lists, requires prior specific permission and/or a fee.

ICMI'12, October 22-26, 2012, Santa Monica, CA, USA.

Copyright 2012 ACM 978-1-4503-1467-1/12/10 ...\$15.00.
To help achieve this, museums are increasingly being equipped with interactive technology. Museums have started to offer handheld devices that provide supplementary information on the spot and that additionally allow visitors to specify exhibits for which they would like to retrieve related information later. For instance Hsi [10] conducted a study in a museum with such an electronic guide. One of the main findings from this study was that the technology isolated the visitors from their surroundings because they wore headsets and that they tended to focus on the device, instead of on the rest of the museum. However, social interaction is an important part of learning [5]. Therefore museums have a growing interest in the use of novel technologies that support collaborative interaction between children [24]. Lately, the use of interactive multi-touch tables in museums receives considerable interest because they facilitate collaborative interactions: they provide space and give access to multiple colocated visitors [9]. In the study reported in [23] the use of technology by young children in the context of a museum visit added a social dimension to the museum visit because it supported and invoked interaction and collaboration. Klopfer et al. [11] introduced an interactive game that aimed to engage visitors more deeply and broadly in museum exhibits and that encouraged collaboration between visitors. Hall and Bannon [7] articulated design guidelines for novel technology to enhance children's educational experience in museums, including collaboration, engagement and active participation and interpretation.

This paper presents findings from a study in Museon ${ }^{1}$, an educational museum with a permanent exhibition 'Your World, My World' about humans and their relation with nature, culture, society, science and technology. The study was part of the European project PuppyIR that had as a main objective to help children search the internet in a safe and child-friendly way and to develop new interaction paradigms that allow children to interact with information in an intuitive way.

In Museon children can choose to do an electronic quest. In this study, we wanted to find out whether personalization of the quest would have an effect on the children's enjoyment. Hence half of the participants of the study used a multi-touch table at the beginning of their museum visit, to personalize the quest. Three or four children simultaneously interacted with the multi-touch table where they chose topics of interest from the exhibition. The choice of the children was used to automatically generate the electronic quest for their visit. The other half of the children received a non-personalized quest, like the ones that are normally

\footnotetext{
${ }^{1}$ http://www.museon.nl
} 
used in Museon. They were also grouped in groups of three or four but they started with the quest immediately. At the table and during the quest children were allowed to collaborate but they did not get instructions to do so. The main goal of the study was to find out whether personalization of the quest actually did enhance enjoyment but we were also interested in whether there was an effect on collaboration as well. Since touch tables are known to facilitate collaborative interactions [9], the interaction with the touch table might have influenced collaboration during the quest as well.

In the next section we will present related work on touch table interaction, interest and personalization. Section 3 will present the context in which the experiment took place. In section 4 we will describe the setup of the experiment and we will motivate the way we measured enjoyment and intrinsic motivation with results from a former pilot study. The results of the experiment will be presented in section 5, followed by a discussion and conclusions in section 6 .

\section{RELATED WORK}

The educational benefits of touch table interaction for children have been investigated before. For instance Sluis et al. [21] used an augmented tabletop application that supported children in learning to read. Africano et al. [1] investigated a more general application that has been tested with exercises in reading, writing and mathematical skills.

Touch table interfaces were found to be suitable for multi-user simultaneous interaction [8], to promote group interaction and discussion [25] and to facilitate collaboration [19, 9, 2]. Moreover, tabletop interfaces were found to be engaging [25] and to allow for playful interaction and an enjoyable user experience [14] while keeping the technology in the background [6]. Enjoyment and fun have been found to support and deepen learning and to facilitate engagement and motivation [15].

In the museum context Zancanaro et al. [24] developed Story Table, a multi-touch table application for collaborative storytelling. It was designed as a tool that helps children reflect on their experience in the museum. Story Table gives children an active role in re-elaborating the material and creating new material collaboratively.

Correia et al. [4] designed and evaluated a multi-touch interactive tabletop application for a contemporary art exhibition with many visitors. One of their main findings was that most visitors engaged in further virtual exploration of the exhibition in order to obtain more information and provide feedback.

The importance of the concept of interest for learning was pointed out by Schiefele [x] who proposed to do future research on interest and motivation. In a follow-up study, Krapp [x] reviewed studies that showed that the concept of interest is positively related to, amongst others, allocation of attention, the use of learning strategies, and quality of experience.

According to Reeve $[\mathrm{x}]$, interest and enjoyment both contribute to intrinsic motivation in a different way. From his experiments he concluded that interest motivates individuals towards exploration and investigation while the motivational effects of enjoyment are the willingness to continue and persist in the activity.

Cordova and Lepper [x] examined the effects of personalization of an educational activity on the learning process of children.
They personalized several features in the learning context in order to associate the learning activities with characters and objects of interest to the child. They showed that personalization increased, amongst others, children's motivation and depth of engagement in learning.

\section{CONTEXT OF THE EXPERIMENT}

The museum where we did the experiment (Museon in the Hague, the Netherlands) is an educational museum that is visited by children with their parents or grandparents and by school classes. Museon has the aim of educating people, in particular children, in such a way that they also enjoy themselves.

Museon has an electronic quest that children can choose to do during their visit. The quest makes use of many terminals, about 120, with touch input and a bar code scanner. These terminals are available all over the exhibition area. Figure 1 shows children answering a question at a terminal. The admission tickets have a bar code on the back that can be scanned at a terminal. The first time a ticket is used with one of the terminals the visitor is asked to register his or her name. Then a quest is generated with 12 questions about different topics in the exhibition area. When the admission ticket is scanned at any one of the terminals, the next question appears. If the visitor has to move to another area in the exhibition to find the answer, he or she can use an available terminal in that area and the question will re-appear. Once the question is answered the visitor gets immediate feedback whether or not the answer is correct and why this is the case. The question re-appears until the correct answer is given or after a fixed number of attempts, in which case the correct answer is given and a new question is displayed. To avoid that the children just find the right answer by trial and error, every wrong answer is counted and decreases the overall performance value that is presented on the screen.

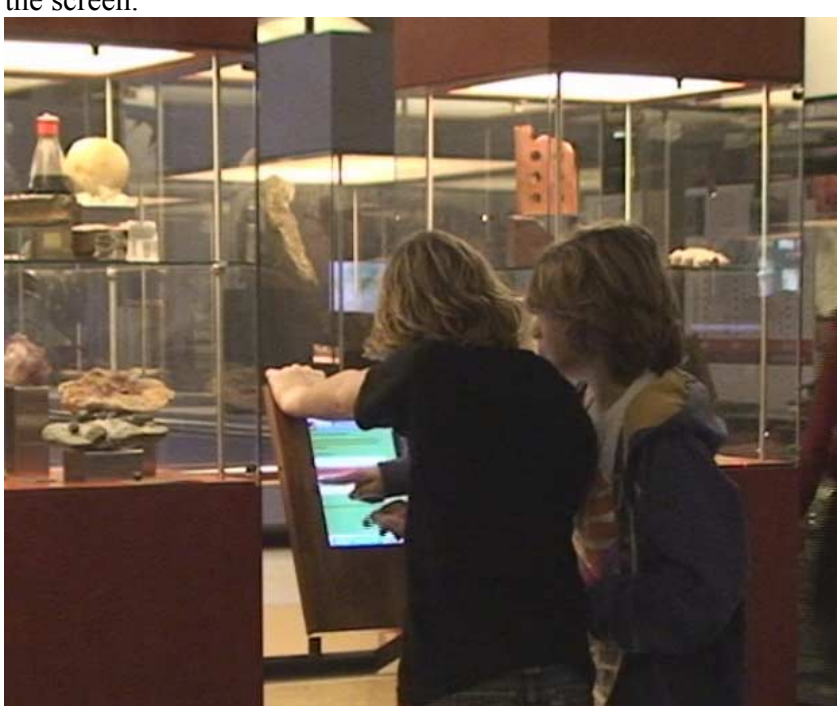

Figure 1. Children answer a question at a terminal.

In the experiment we used this existing infrastructure and enhanced it with a multi-touch table that was placed in the museum's entrance area (see Figure 2). The table can identify fiducial markers. Physical objects with a marker can be placed on top of the table and be identified by the system through a unique identifier. 
These fiducial markers were used in the experiment with the museum's admission tickets. Each participant received a ticket with a fiducial marker at one side and a bar code at the other side. Hence the ticket could be used as an identifier at the table and at the terminals in the exhibition area.

Up to four users could use the table simultaneously. They registered themselves by placing the admission ticket at the table. Once four users registered themselves (or if fewer users were available after a certain period of time) the initial game started with a small introduction.

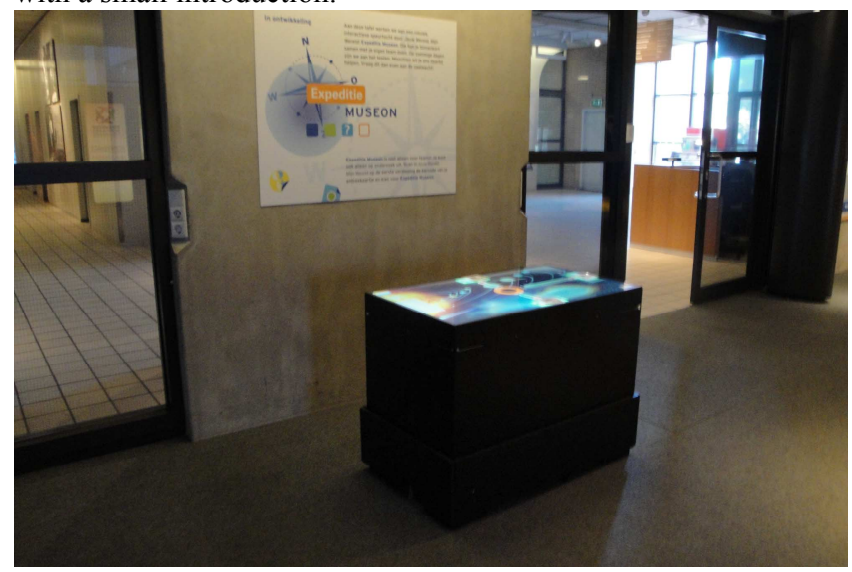

Figure 2. Multi-touch table in the entrance hall of Museon.

The purpose of the game was to let the players choose 12 topics that are part of exhibits in the permanent exhibition. The topics were represented by pictures and a title and were placed in a slowly rotating circle. When touched and/or dragged they grew in size and showed some more text to inform the user about the represented topic. To be accessible from each side of the table the pictures automatically changed their orientation by rotating towards the user's position. Figure 3 presents a snapshot of participants in the experiment playing the initial game.

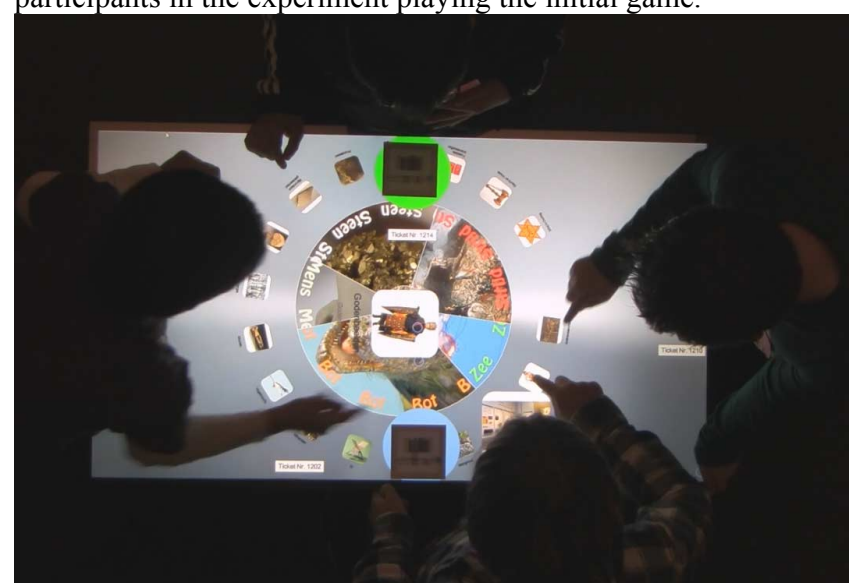

Figure 3. Snapshot of children playing the initial game.

The children could move the pictures around the table and pass them on to each other. When a picture was not touched for a while it disappeared back into the circle but could be dragged outside again at any time.

If a child was interested in a certain exhibit or topic the picture could be dropped into the middle of the circle. Up to 12 different pictures could be selected and thereby the topics that were used to create the electronic quest were selected. The group did not have to choose only topics everybody was interested in. Instead, the initial game at the table offered the possibility to either individually or collaboratively explore the topics that were available in the museum exhibition. When 12 pictures had been chosen, the topics were automatically stored in a central database and for each child a personal quest with 12 questions about the 12 chosen topics was generated. After that the children took their admission tickets and went to the exhibition room where they used the bar code side of the ticket to access the questions of their quest at the terminals

After all the children of a group had answered all 12 questions of the quest in the exhibition area they went to the multi-touch table as a group, to play the final game. They had to register themselves using their tickets after which the final game started immediately. The final game at the table had an interface that resembled the interface of the initial game. The slowly rotating circle with pictures of topics appeared again in the middle but this time the pictures displayed were related to the topics from the questions the children answered. Analogous to the initial game children could drag pictures out of the circle to view further information (now more extended) or show them to each other at the table. Instead of choosing topics and dragging them into a common circle in the middle, now the pictures could be dropped into a private circle that appeared in one of the corners of the table. See Figure 4 for a snapshot of participants in the experiment playing the final game.

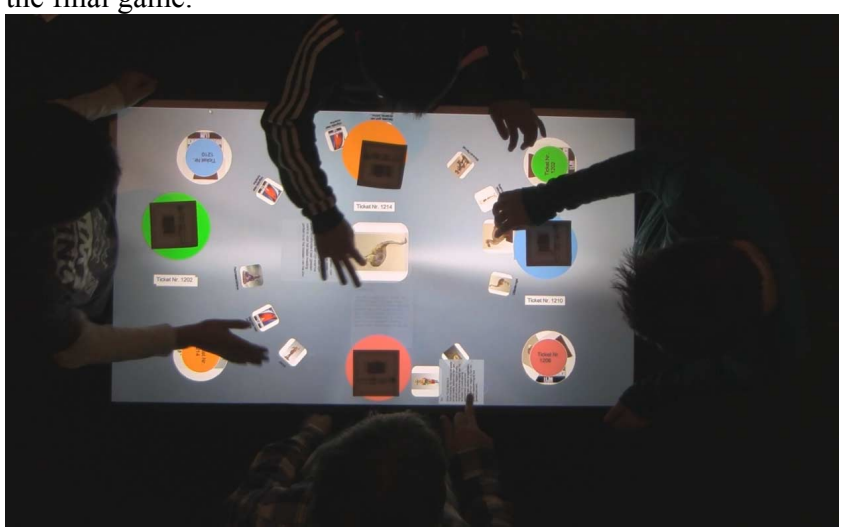

Figure 4. Snapshot of children playing the final game.

The main idea behind the final game was to give the children the opportunity to create their own, personalized virtual museum catalogue. It is common practice that museums offer catalogues with information and photos of exhibits. The final game aimed to offer children an intuitive way of creating such a catalogue by collecting topics and exhibits they liked during their tour. With the unique identification on the admission ticket it will be possible for the children to access the information after the visit from outside the museum, for instance at home or at school, allowing an extended search for related data.

\section{SETUP OF THE EXPERIMENT}

An experiment was conducted in Museon as to find an answer to the question whether personalization of the interactive quest enhanced the fun experience of doing the quest. The quest was personalized by the participants by playing a game at a multitouch table. In addition, we evaluated whether the combination of the interaction at the table and the personalization of the quest supported and invoked collaboration between the participants of the experiment. 


\subsection{Experimental conditions}

The experimental setup consisted of two conditions, a condition with a personalized quest and a control condition with a nonpersonalized quest. In the condition with the personalized quest the children started the museum visit at the multi-touch table, where they selected topics they were interested in by choosing images that represented these topics. The chosen topics were parts of the exhibition and were used to determine a route through the exhibition room of the museum. Based on the results of the initial game, the children received a personalized quest of twelve questions to be answered at twelve different exhibits. In the control condition, the children did a non-personalized electronic quest, similar to the quest children can normally choose to do when they visit Museon. Hence in this condition the children started the museum visit with the quest and they did not play the initial game at the table.

\subsection{Participants}

The experiment took place at Museon in the Hague in the Netherlands. Two classes from a Dutch primary school in the Hague (Nutsschool M.M. Boldingh), a school located close to Museon, participated in the study. In total there were 48 children who participated, 21 children aged 11-12 years old that were in their final year of primary education and 27 children of 10-11 years old from the pre-final year.

\subsection{Procedure}

The teachers formed groups of four children (sometimes three if necessary) before the museum visit. The children of the pre-final year were divided into seven groups and the children of the final year were divided into six groups. In total seven groups (four from the pre-final year and three from final year, in total 26 children) were assigned to the condition with the personalized quest and six groups (three groups from both the pre-final and the final year, in total 22 children) were assigned to the control condition with the non-personalized quest.

The groups were given an explanation about the procedure of the experiment. They were also told that they could ask for help if something was not clear. Then the groups started with either the initial game or the quest, depending on the condition they were assigned to. After all members of a group had finished the quest, they went to the multi-touch table to play the final game. All teams played the final game, also the teams that did not start at the table. While playing the final game the children could get further information about the exhibits they had visited and they could choose topics/exhibits they were most interested in. Their choices were used later at school, using a web application also developed for the PuppyIR project. This paper does not include the evaluation of that web application.

After the final game the children handed in their tickets and they filled in a paper questionnaire that they gave to their teacher afterwards.

\subsection{Measures}

A questionnaire was used to measure the constructs enjoyment and collaboration. Subscales for the constructs were inserted in the questionnaire. The complete questionnaire can be found in the user evaluation toolkit on the PuppyIR site $^{2}$. the questionnaire.

${ }^{2}$ http://www.puppyir.eu/results/user-evaluation-toolkit

\subsubsection{Enjoyment and intrinsic motivation}

We measured enjoyment in three different ways that each focus on a different aspect of enjoyment. The first measure used is the Smileyometer taken from the Fun Toolkit for children by Read and MacFarlane [16].

The Smileyometer was especially designed for children. It is based on a 5-point Likert scale and uses five smileys. See Figure 5 for an example. For each of the three parts of the museum visit (initial game, quest, final game) the children used the Smileyometer to answer the question "How much fun was it to do that part?"

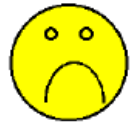

Awful

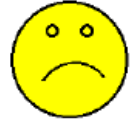

Not very good

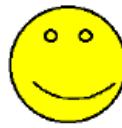

Good

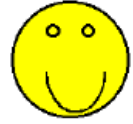

Really good

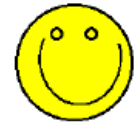

Brilliant
Figure 5. The Smileyometer.

The answers on the Smileyometer were re-coded from 1 (for awful) to 5 (for brilliant). According to Read and MacFarlane [17], the Smileyometer is not very useful for young children. They did a study in which almost half of the children aged between 7 and 9 used the highest score and they found a significant difference in the mean score of these young children and the mean score of an older age group (ages 12 and 13).

The results of our first pilot study in Museon, in which 36 children took part, confirmed this difference between age groups [22]. The data indicated that younger children had a higher tendency to select the highest ratings, but did select non-extreme scores as well. Hence we argued that the Smileyometer is probably a useful tool for children of 10-12 years old and decided to use it in this study again.

The second enjoyment related measure we used is the AgainAgain table (see Figure 6), also from the Fun Toolkit [16]. The Again-Again table measures engagement. The children were asked whether they would like to do the activities (initial game, quest, final game) again. This measure is based on the knowledge that people like to do fun things again.

Read and MacFarlane [17] did another study where they investigated the relation between results obtained using the Smileyometer and results obtained using the Again - Again table. They found very strong correlations and concluded that both tools measure the same construct.

\section{Would you like to do it Again?}

\begin{tabular}{|c|c|c|c|}
\hline & Yes & Maybe & No \\
\hline Museon quest & $\checkmark$ & & \\
\hline
\end{tabular}

Figure 6. The Again-Again table.

In our first pilot study in Museon we used both the Smileyometer and the Again-Again table. Hence we could easily investigate the relation between the results as well by carrying out non- 
parametric correlations. We also found strong correlations between the results of the Smileyometer and the Again-Again table, for all measurements. The results are presented in Table 1.

Table 1. Correlations between the scores on the Smileyometer and the Again-Again table in the first pilot study

\begin{tabular}{|l|l|c|l|}
\hline Activities & $\mathbf{N}$ & $\begin{array}{c}\text { Spearman's } \\
\text { rho }\end{array}$ & Significance \\
\hline Initial game & 36 & 0.447 & $p<0.01$ \\
\hline Quest & 35 & 0.620 & $p<0.0005$ \\
\hline Final game & 35 & 0.562 & $p<0.0005$ \\
\hline
\end{tabular}

These results seem to support the conclusion of Read and MacFarlane [17]. However, when we looked at age differences again we found that these correlations varied for different age groups. For the older children (above 10 years old) the correlations were weaker and for two of the three activities not even significant. These older children rated the Smileyometer questions (if they liked it) very high but still sometimes answered 'maybe' or 'no' on the questions if they wanted to do it again. Hence we decided to use both measures again because the difference in emphasis of the evaluation (judging the software versus giving your own opinion on what you would like to do again) might have influence in some cases.

The third measure we used to measure enjoyment in the experiment was the Children IMI interest/enjoyment scale. This scale was derived from the Intrinsic Motivation Inventory (IMI), a multidimensional measurement device which can be modified to fit specific activities (University of Rochester, retrieved $2012^{3}$ ). The interest/enjoyment subscale we used is considered to be the self-report measure of intrinsic motivation and was developed for use by adults. Although this scale basically also measures fun, like the tools of the Fun Toolkit, this scale measures interest as well. If we manage to get a reliable scale for children here, the constructs enjoyment and interest are coupled to get a measure of intrinsic motivation, a very important factor for learning.

The IMI consists of seven statements:

- I enjoyed doing this activity very much.

- This activity was fun to do.

- I thought this was a boring activity.(R)

- $\quad$ This activity did not hold my attention at all.(R)

- I would describe this activity as very interesting.

- I thought this activity was quite enjoyable.

- While I was doing this activity, I was thinking about how much I enjoyed it.

All these statements are rated on a 7-point Likert scale where 1 represents 'not at all true', 4 represents 'somewhat true' and 7 represents 'very true'.

We adapted the IMI interest/enjoyment scale to make it more suitable for children. We reversed the two negatively formulated statements. Hence the third and fourth statements were changed into:

3 http://www.selfdeterminationtheory.org/questionnaires/10questionnaires $/ 50$
- I thought this was an exciting activity

- This activity held my attention very well

In addition, we used a 5-point scale with 'Totally disagree' at the negative end and 'Totally agree' at the positive end and we used the smileys from the Smileyometer. See Figure 7.
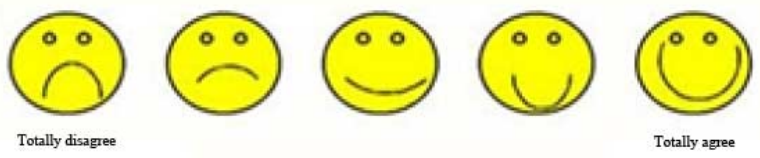

Figure 7. Answer categories of the Children IMI interest/enjoyment scale.

The new Children IMI interest/enjoyment scale was used to measure enjoyment during the quest. It is part of the User Evaluation Toolkit on the PuppyIR site ${ }^{4}$

\subsubsection{Collaboration}

To measure perceived collaboration, we added three items to the questionnaire:

- I tried very hard to support others in doing the quest

- I collaborated with my classmates a lot

- I liked supporting others during the quest

We also observed the children while they did the quest but it was very difficult to keep track of the many things that happened because many groups did the quest almost simultaneously. Hence no systematic observation results could be obtained.

\section{RESULTS}

\subsection{Enjoyment and intrinsic motivation}

Table 2 presents the results of Enjoyment for the three main parts (initial game, quest, final game), as measured with the Smileyometer on a 5-point Likert scale.

Using the Mann-Whitney test no significant differences were found between the two experimental groups on enjoyment of the quest and the final game.

We found significant differences between the pre-final and the final year of primary education. Table 3 shows the descriptive statistics per age group. Even though the difference in age is only one year, for the quest the scores measured with the Smileyometer were significantly higher for children from the pre-final year of primary education than for children from the final year (MannWhitney $\mathrm{U}=121.0, p$ (two-tailed) $<0.0005$ ).

\footnotetext{
${ }^{4}$ See http://www.puppyir.eu/results/user-evaluation-toolkit
} 
Table 2. Enjoyment measured with the Smileyometer for the three main parts

\begin{tabular}{|l|l|l|l|}
\hline Activities & $\mathbf{N}$ & $\begin{array}{l}\text { Personalized } \\
\text { quest }\end{array}$ & $\begin{array}{l}\text { Non- } \\
\text { personalized } \\
\text { quest }\end{array}$ \\
\hline $\begin{array}{l}\text { Enjoyment } \\
\text { initial game }\end{array}$ & 26 & $\begin{array}{l}\text { Mean=3.77, } \\
\mathrm{SD}=0.77\end{array}$ & - \\
\hline $\begin{array}{l}\text { Enjoyment } \\
\text { quest }\end{array}$ & 48 & $\begin{array}{l}\text { Mean=3.50, } \\
\mathrm{SD}=0.95\end{array}$ & $\begin{array}{l}\text { Mean=3.00, } \\
\mathrm{SD}=1.27\end{array}$ \\
\hline $\begin{array}{l}\text { Enjoyment } \\
\text { final game }\end{array}$ & 48 & $\begin{array}{l}\text { Mean=3.54, } \\
\mathrm{SD}=0.86\end{array}$ & $\begin{array}{l}\mathrm{Mean}=3.95, \\
\mathrm{SD}=1.09\end{array}$ \\
\hline
\end{tabular}

For the initial game the differences between the scores of the prefinal and the final year were marginally significant (MannWhitney $\mathrm{U}=47.0, \quad p \quad($ two-tailed $)=0.061)$. No significant difference was found for the final part.

Table 3. Difference in enjoyment between age groups as measured with the Smileyometer.

\begin{tabular}{|l|l|l|l|l|l|}
\hline Activities & Age group & $\mathbf{N}$ & Mean & SD & Signific. \\
\hline $\begin{array}{l}\text { Enjoyment } \\
\text { initial game }\end{array}$ & Pre-final & 16 & 4.00 & 0.82 & $p=0.061$ \\
& Final year & 10 & 3.40 & 0.52 & \\
\hline Enjoyment & Pre-final & 27 & 3.78 & 1.05 & $p<0.0005$ \\
quest & Final year & 21 & 2.62 & 0.87 & \\
\hline $\begin{array}{l}\text { Enjoyment } \\
\text { final game }\end{array}$ & Pre-final & 27 & 3.74 & 0.90 & $p=0.948$ \\
\hline
\end{tabular}

The results for enjoyment as measured by the Again-Again table are shown in Table 4. Chi-square tests showed that there was no significant difference between the two conditions for the quest part of the visit. For the final game there was a significant difference: children who already used the multi-touch table at the start of the visit were more positive to use the table again than children who used the table for the first time in the final game (chi-square $=6.06, d f=2, p=0.048$ ).

Table 4. Enjoyment measured with the Again-Again table for the three main parts.

\begin{tabular}{|l|l|c|c|c|}
\hline Activities & Answer & $\begin{array}{l}\text { Table } \\
\text { at start }\end{array}$ & $\begin{array}{l}\text { No Table } \\
\text { at start }\end{array}$ & Total \\
\hline \multirow{3}{*}{$\begin{array}{l}\text { Again-Again } \\
\text { initial game }\end{array}$} & No table & 0 & - & \\
\cline { 2 - 5 } & Maybe & 10 & - & \\
\cline { 2 - 5 } & Yes & 16 & - & \\
\hline \multirow{3}{*}{$\begin{array}{l}\text { Again-Again } \\
\text { quest table }\end{array}$} & No & 5 & 6 & 11 \\
\cline { 2 - 5 } & Maybe & 9 & 7 & 16 \\
\cline { 2 - 5 } & Yes & 12 & 8 & 20 \\
\hline \multirow{3}{*}{$\begin{array}{l}\text { Again-Again table } \\
\text { final game }\end{array}$} & No & 2 & 5 & 7 \\
\cline { 2 - 5 } & Maybe & 7 & 10 & 17 \\
\cline { 2 - 5 } & Yes & 16 & 6 & 22 \\
\hline
\end{tabular}

We investigated the relation between the results on the Smileyometer and the Again-Again table by carrying out nonparametric correlations. We again found strong correlations between the results of the Smileyometer and the Again-Again table, for all measurements. The results are presented in Table 5.

Table 5. Correlations between the scores on the Smileyometer and the Again-Again table.

\begin{tabular}{|l|l|c|l|}
\hline Activities & $\mathbf{N}$ & $\begin{array}{c}\text { Spearman's } \\
\text { rho }\end{array}$ & Significance \\
\hline Initial game & 26 & 0.613 & $p<0.001$ \\
\hline Quest & 47 & 0.703 & $p<0.0005$ \\
\hline Final game & 46 & 0.456 & $p<0.001$ \\
\hline
\end{tabular}

When we looked at age differences again we found that these correlations varied for different age groups. For the children of the pre-final year the correlations for all activities were strong (for the initial game $p=0.004$, for the quest $p<0.0005$ and for the final game $p<0.0005)$. For the children of the final year only the results for the quest were correlated but the correlation was much weaker $(p=0.025)$. For the initial game and the final game no significant correlations were found between the results on the Smileyometer and the results on the Again-Again table.

Enjoyment/Intrinsic motivation was measured by the Children IMI interest/enjoyment scale. This adapted scale appeared to be very reliable for the children who participated in our study (Cronbach alpha $=0.923)$. Hence we used the mean score on this enjoyment/motivation scale in our analyses.

The mean score on this Enjoyment scale was $3.54(\mathrm{SD}=1.01)$ on a 5 -point scale which is quite high but not extremely high and variability seems to be high enough, indicating that the scale is useful for children of 10-12 years old. We used the MannWhitney test to check whether there was a significant difference between the scores of the two experimental conditions on this enjoyment/motivation scale. No significant difference was found for enjoyment/motivation doing the quest. We did find significant differences between the results of the class in the pre-final year of primary education (10-11 years old) and the class in the final year (11-12 years old). The mean enjoyment/motivation score of younger age group was $3.96(\mathrm{SD}=0.88)$ and the mean score of older age group was $3.003(\mathrm{SD}=0.94)$. This mean score was significantly higher for the younger children as compared to the older children (Mann-Whitney $\mathrm{U}=123.5, p=0.001$ ).

\subsection{Collaboration}

We tested the three items of the questionnaire that measured perceived collaboration on reliability. The Cronbach's alpha for the three questions was 0.649 which was not really high enough (we used a threshold of 0.7). By deleting the question "I collaborated with my classmates a lot" we got a 2 item scale with a Cronbach's alpha of 0.763 . Hence we analyzed this scale about supporting others and the question about perceived collaboration separately.

The mean score on the supporting others scale was 3.73 $(\mathrm{SD}=0.87)$ for the children in the condition with the personalized quest and $3.52(\mathrm{SD}=1.13)$ for the children in the control condition. According to the Mann-Whitney test there was no significant difference between the two experimental groups. For perceived collaboration the mean scores of the experimental groups were 
$3.77(\mathrm{SD}=0.95)$ for the personalized condition and 3.55 $(\mathrm{SD}=1.10)$ for the control condition. Again the Mann-Whitney test showed the difference in means was not significant. Using the Mann-Whitney test we did not find any significant differences between the children of the two age groups on perceived collaboration and on the supporting others scale.

\section{DISCUSSION AND CONCLUSIONS}

We presented the results of a study in an educational museum. Children of 10-12 years old followed a tour with an electronic quest through the permanent exhibition of the museum. The children were assigned to two experimental conditions. One condition reflected the normal situation in the museum: children did a non-personalized quest that was generated with randomly chosen topics from the exhibition. The other group used a multitouch table at the start to personalize the quest.

No significant differences were found between the two experimental conditions on enjoyment as measured by the Smileyometer and the Children IMI interest/enjoyment scale. Moreover we did not find any significant differences between the experimental conditions on collaboration. We did find one significant difference between the conditions: on the Again-Again table measure there was a significant difference for the final game. Children who already used the multi-touch table at the start of the visit were more positive to use the table again than children who only used the table for the final game. The only explanation we can think of is that the children did not fully understand the purpose of the final game. Either this was more the case for the children that did not have experience with the multi-touch table yet or this was equally true for the children that played the initial game but this last group still remembered the positive experience of playing the initial game and that was reflected in their opinion. However, the results of the other enjoyment measure on the final game were similar for the two experimental conditions hence no conclusive explanation can be given.

Getting back to our main research question: we did not find evidence that personalization of the quest by addition of an initial game at the multi-touch table enriched the children's fun experience during the quest. The results on the enjoyment scales were quite high for all children but not so high that we think a ceiling effect will have caused the lack of evidence for positive effects of personalization. In addition, we did not find any evidence that the combination of the two differences between the conditions - the extra interaction with the multi-touch table and the resulting personalization of the quest - enhanced collaboration between the participants of the experiment. Of course as an extra attraction, interaction with the multi-touch table will have a value of its own.

Although this was originally not the focus of our study, we found significant differences between age groups: children from the prefinal year of primary education scored higher than children from final year on enjoyment of the quest and initial game as measured by the Smileyometer. In addition the overall mean score on the Children IMI interest/enjoyment scale was significantly higher for children from the pre-final year than for children from the final year.

We found strong correlations between the results of the Smileyometer and the Again-Again table, for all measurements. When we looked at age differences we found that these correlations varied for different age groups. For younger children the correlations for all measurements were strong, for older children (above 10 years of age) the correlations were much weaker or absent. From this we conclude that the Again-Again table is valuable to use alongside the Smileyometer, especially for children above 10 years old. When judging the software the older children seem to over-score to be polite, while when giving their opinion on what they would like to do again they express their doubts.

Probably the most important result of this evaluation is the fact that we adapted the IMI scale for adults to get a reliable scale to measure intrinsic motivation of children of 10-12 years old. It would be interesting to validate this Children IMI interest/enjoyment scale in a larger experiment and with different age groups.

\section{ACKNOWLEDGMENTS}

The research leading to these results has received funding from the European Community's Seventh Framework Programme FP7/2007-2013 under grant agreement $n^{\circ} 231507$.

\section{REFERENCES}

[1] Africano, D., Berg, S., Lindbergh, K., Lundholm, P., Nilbrink, F., and Persson, A. 2004. Designing tangible interfaces for children's collaboration. In $\mathrm{CHI}$ '04 Extended Abstracts on Human Factors in Computing Systems. ACM, New York, NY, 853-868.

[2] Buisine,S., Besacier, G., Aoussat,A. and Vernier,F. 2012. How do interactive tabletop systems influence collaboration? In Computers in Human Behavior. 28, 1, 49-59.

[3] Cordova, D.L. and Lepper M.R. 1996. Intrinsic motivation and the process of learning: Beneficial effects of contextualization, personalization, and choice. In Journal of Educational Psychology, 88, 4, 715-730.

[4] Correia, N. Mota, T, Nóbrega, R., Silva, L. and Almeida, A. 2010. A multi-touch tabletop for robust multimedia interaction in museums. In ACM International Conference on Interactive Tabletops and Surfaces. ITS '10. ACM, New York, NY, 117-120.

[5] Gage, N.L. and Berliner, D. 1998. Educational Psychology. 6th edition,. Wadsworth Publishing.

[6] Geller, T. 2006. Interactive Tabletop Exhibits in Museums and Galleries. IEEE Computer Graphics and Applications. 26, 5, 6-11.

[7] Hall, T. and Bannon, L. 2005. Designing ubiquitous computing to enhance children's interaction in museums. In Proceedings of the 2005 conference on Interaction Design and Children (Boulder, Colorado). IDC'05. ACM, New York, NY, 62-69.

[8] Hinrichs, U., Hancock, M., Carpendale, S., and Collins, C. 2007. Examination of Text-Entry Methods for Tabletop Displays. In $2^{\text {nd }}$ IEEE International Workshop on Horizontal Interactive Human-Computer Systems. TABLETOP '07. 105-112.

[9] Hornecker, E. 2008, “I don't understand it either, but it is cool" - Visitor interactions with a multi-touch table in a museum. In $3^{\text {rd }}$ IEEE International Workshop on Horizontal Human-Computer Systems. TABLETOP ’08. 113-120. 
[10] Hsi, S. 2003. A study of user experiences mediated by nomadic web content in a museum. In Journal of Computer Assisted Learning. 19, 3, 308-319.

[11] Klopfer, E., Perry, J., Squire, K., Jan, M.F. and Steinkuehler, C. 2005. Mystery at the museum: a collaborative game for museum education. In Proceedings of the 2005 conference on Computer-Supported Collaborative Learning : learning 2005: the next 10 years! CSCL '05. 316-320.

[12] Kotler, N. and Kotler, P. 2000. Can museums be all things to all people?: Missions, goals, and marketing's role. Museum Management and Curatorship. 18, 3, 271-287.

[13] Krapp, A. 1999. Interest, motivation and learning: An educational-psychological perspective. In European Journal of Psychology of Education, XIV, 1, 23-40.

[14] Mahmud, A., Mubin, O., Renny Octavia, J., Shahid, S., Yeo, L., Markopoulos, P., Martens, J.-B, and Aliakseyeu, D. 2007. Affective Tabletop Game: A New Gaming Experience for Children. In $2^{\text {nd }}$ IEEE International Workshop on Horizontal Interactive Human-Computer Systems. TABLETOP'07. 4451.

[15] Price S., Rogers, Y., Scaife, M., Stanton, D. and Neale, H. 2003. Using 'tangibles' to promote novel forms of playful learning. In Interacting with Computers, 15, 2, 169-185.

[16] Read, J.C. and MacFarlane, S. 2002. Endurability, engagement and expectations: Measuring children's fun. In Proceedings of the 2002 Conference on Interaction Design and Children. IDC'02. ACM, New York, NY, 1-23.

[17] Read, J.C. and MacFarlane, S. 2006. Using the Fun Toolkit and other survey methods to gather opinions in Child Computer Interaction. In Proceedings of the 5th International Conference on Interaction Design and Children. IDC'06. ACM, New York, NY, 81-88.
[18] Reeve, J. 1989. The interest-enjoyment distinction in intrinsic motivation. In Motivation and Emotion, 13, 2, 83103.

[19] Rogers, Y. and Lindley, S. 2004. Collaborating around vertical and horizontal large interactive displays: which way is best? In Interacting with Computers, 16, 6, 1133-1152.

[20] Schiefele, U. 1991. Interest, learning, and motivation. In Educational Psychologist, 26, 3 and 4, 299-323.

[21] Sluis, R., Weevers, I., and Van Schijndel, C. 2004. Read-It: five-to-seven-year-old children learn to read in a tabletop environment. In Proceedings of the 2004 Conference on Interaction Design and Children. IDC'04. ACM, New York NY, 73-80.

[22] Van der Sluis, F., Van Dijk, E.M.A.G. and Perloy, B. 2012. Measuring fun and enjoyment of children in a museum: Evaluating the Smileyometer. In Measuring Engagement: Affective and Social Cues in Interactive Art and Media. Special session at Measuring Behavior 2012. Accepted, to appear.

[23] Yiannoutsou, N. , Papadimitriou, I., Komis, V. and Avouris, N. 2009. Playing with Museum Exhibits: Designing Educational Games Mediated by Mobile Technology. In Proceedings of the 8th International Conference on Interaction Design and Children. IDC '09. ACM, New York, NY, 6-9.

[24] Zancanaro, M., Pianesi, F., Stock, O., Venuti, P., Cappelletti, A., Iandolo, G., Prete, M., \& Rossi, F. (2007). Children in the museum: an environment for collaborative storytelling. PEACH-Intelligent Interfaces for Museum Visits. 165-184.

[25] Zuckerman, O., Arida, S., and Resnick, M. 2005. Extending tangible interfaces for education: digital montessori-inspired manipulatives. In Proceedings of the SIGCHI conference on Human Factors in computing systems. CHI'05. ACM, New York, NY, 859-868. 